\title{
Article
}

Mycosphere

Doi 10.5943/mycosphere/11/1/6

\section{One step closer to unravelling the origin of Russula: subgenus Glutinosae subg. nov.}

\section{Buyck $\mathbf{B}^{1^{*}}$, Wang $\mathrm{X}-\mathrm{H}^{2}$, Adamčíková $\mathrm{K}^{3}$, Caboň $\mathbf{M}^{4}$, Jančovičová $\mathrm{S}^{5}$, Hofstetter $\mathrm{V}^{6}$ and Adamč́k $\mathrm{S}^{4}$}

\author{
${ }^{1}$ Institut pour la Systématique, Evolution, Biodiversité (ISYEB), UMR 7205, Case Postale 39 Muséum national \\ d'histoire naturelle, Sorbonne Université, CNRS, 12 Rue Buffon, F-75005 Paris, France \\ ${ }^{2}$ CAS Key Laboratory for Plant Diversity and Biogeography of East Asia, Kunming Institute of Botany, Chinese \\ Academy of Sciences, Kunming 650201, P. R. China \\ ${ }^{3}$ Department of Plant Pathology and Mycology, Institute of Forest Ecology, Slovak Academy of Sciences Zvolen, \\ Akademická 2, SK-949 01 Nitra, Slovakia \\ ${ }^{4}$ Institute of Botany, Plant Science and Biodiversity Center, Slovak Academy of Sciences, Dúbravská cesta 9, SK-845 23 \\ Bratislava, Slovakia \\ ${ }^{5}$ Department of Botany, Faculty of Natural Sciences, Comenius University in Bratislava, Révová 39 , SK-811 02 \\ Bratislava, Slovakia \\ ${ }^{6}$ Agroscope Research Station, Department of plant protection, Rte de Duiller 60, 1260 Nyon 1, Switzerland
}

Buyck B, Wang X-H, Adamčíková K, Caboň M, Jančovičová S, Hofstetter V, Adamčík S 2020 One step closer to unravelling the origin of Russula: subgenus Glutinosae subg. nov. Mycosphere 11(1), 285-304, Doi 10.5943/mycosphere/11/1/6

\begin{abstract}
This study reports on the discovery of a new subgenus, Russula subg. Glutinosae, having an Eastern North American - East Asian distribution. A multigene phylogeny places this new subgenus sister with strong support to a well-supported clade composed of subgenera Compactae and Archaeae. It holds only two very rare, northern hemisphere species, the North American $R$. glutinosa and the Asian $R$. glutinosoides sp. nov., thereby adding support to a northern hemisphere origin of the genus. Russula fattoensis is here shown to be a synonym of $R$. glutinosa. Detailed morphological descriptions and illustrations of holotype collections are provided and potential affinities and similarities with other subgenera are discussed. The new subgenus is a perfect illustration of the fact that nBLAST of nrITS does not always provide the appropriate sampling for phylogenetic analyses.
\end{abstract}

Key words - BLAST - China - multi-locus - new subgenus - nrITS - phylogeny - United States

\section{Introduction}

The infrageneric classification of the genus Russula has been much debated lately in the light of recent multi-locus phylogenies (Buyck et al. 2008, Bazzicalupo et al. 2017, Looney et al. 2016). The latest genus phylogeny (Buyck et al. 2018) was based on a very representative sampling of the world's diversity of the genus and it proposed to recognize seven well-supported subgenera that were largely congruent with features of ectomycorrhizal anatomy.

In this contribution, we report on the rather unexpected discovery of yet another new, but very small subgenus, composed of merely two extremely rare species that were previously assumed to belong to Russula subg. Archaeae Buyck \& V. Hofst. (see Buyck \& Adamčík 2013). Subgenus 
Archaeae has always been interpreted as a good candidate for the most ancient lineage within the genus. It was hitherto unique in being composed of species with extremely small spores, at least when compared to those of other Russula (Buyck 1998, Buyck et al. 2017). However, the basidiospores of species in subg. Archaeae are slightly smaller in size compared to those of genus Multifurca Buyck \& V. Hofst. and near-identical to those of some corticiaceous Russulaceae (Buyck et al. 2008). The here newly introduced subgenus shares with subg. Archaeae similarly small spores as well as the often puzzling resemblance of its fruiting bodies to certain species in Hygrophoraceae, a feature first reported by Heim (1938).

The first of the two species that compose this new subgenus, $R$. glutinosa Fatto, was described from New Jersey (USA) 20 years ago (Fatto 1999). Fatto placed this species in Russula subsect. Lactarioideae Mre, a species assemblage that is part of $R$. subg. Brevipedum Buyck \& V. Hofst. following the latest genus phylogeny (Buyck et al. 2018). As we will demonstrate below, this same species was later described a second time (by means of an extended Latin diagnosis, see Buyck 2004) under the name $R$. fattoensis Buyck. The type specimen of the latter species was collected during joint field excursions by Buyck and Fatto, who - at that time - failed to recognize it as $R$. glutinosa. Because of its hygrophoroid habit, the extremely small spores and some other microscopic similarities, $R$. fattoensis was placed in $R$. sect. Archaeinae Buyck \& Sarnari (Buyck 2004, Buyck \& Adamčík 2013), a section that was later upgraded to subgenus level (in Hongsanan et al. 2015). A detailed and illustrated English description for $R$. fattoensis was never published, hence, a detailed description of the holotype is provided below.

Sequences referring to either $R$. glutinosa or $R$. fattoensis were never part of any published phylogenetic analysis. Yet, a nrITS sequence for $R$. glutinosa (obtained from a specimen collected and identified in the field by the first author during an All Taxa Biodiversity Inventory in Tennessee, USA) had been deposited as early as 2004 in GenBank (EU598202). During a recent field trip to Yunnan, China, one of the collected fruiting bodies there was identified in the field (BB) as $R$. glutinosa (or at least a look-alike of it) and reminded one of us (XHW) of an earlier, possibly contaxic collection from Yunnan. The present study involves all known specimens for the studied species and it provides their highly supported placement in the genus using the same multilocus phylogenetic approach as in the latest phylogeny of the genus (Buyck et al. 2018).

\section{Materials and Methods}

\section{Morphology}

Macroscopic observations of fresh basidiomata are based on the first author's field notes and photographs. The color notations indicated in the descriptions follow Kornerup \& Wanscher (1978). Microscopic features were re-examined and sketched by B. Buyck, S. Adamčík and S. Jančovičová. All microscopic observations and measurements - except for basidiospores - were made in ammoniacal Congo red, after a short aqueous $\mathrm{KOH}$ pretreatment to improve tissue dissociation and matrix dissolution. All elements of the basidiomata were examined for the presence of ortho- or metachromatic contents or incrustations in Cresyl blue as explained in Buyck (1989). Observations and measurements of basidiospores were made in Melzer's reagent. Terminology related to microscopic elements follow Adamčík et al. (2019). Herbarium abbreviations follow Index herbariorum (http://sweetgum.nybg.org/science/ih/).

\section{Nomenclature}

As already evident from the introduction above, the orthography of the names of the various accepted or recently described new subgenera in Russula (see Hongsanan et al. 2015, Buyck et al. 2018) have here been corrected in order to conform to the rules of the Shenzen International Code of Nomenclature for algae, fungi, and plants (Art. 21.2 on names of infrageneric taxa https://www.iapt-taxon.org/nomen/pages/main/art_21.html). 


\section{Extraction, amplification and sequencing}

Total genomic DNA from American samples was extracted from dried material using the EZNA Fungal DNA Mini Kit (Omega) according to manufacturer's recommendations, but with prolonged incubation time of up to $1 \mathrm{hr}$ after addition of the RNA-lytic enzyme. For the two Chinese samples, total DNA was extracted using a CTAB protocol (Doyle \& Doyle 1987). Six molecular markers were amplified (Table 1). The PCR products were purified using Exo-Sap enzymes (Thermo Fisher Scientific, Wilmington, DE) or the Qiaquick PCR Purification Kit (Qiagen, Hilden, Germany) or gel-purified for the Chinese samples. Samples were sequenced by the Seqme company (Dobříš, Czech Republic) and Sangon Biotech company (Shanghai, China).

Table 1 List of molecular markers, primers and cycling protocols used in this study. (*) refers to newly designed primers by XH Wang.

\begin{tabular}{|l|l|l|}
\hline Molecular marker & Primers & $\begin{array}{l}\text { Cycling } \\
\text { protocol }\end{array}$ \\
\hline $\begin{array}{l}\text { Internal transcribed spacer regions } \\
\text { of ribosomal DNA (nrITS) }\end{array}$ & $\begin{array}{l}\text { ITS1F+ITS4 (White et al. 1990, Gardes \& Bruns } \\
1993)\end{array}$ & $\begin{array}{l}\text { Ondrušková et } \\
\text { al. 2017 }\end{array}$ \\
\hline $\begin{array}{l}\text { Partial large subunit ribosomal } \\
\text { DNA (LSU) }\end{array}$ & LROR+LR5 (Moncalvo et al. 2000) & $\begin{array}{l}\text { Pastirčáková et } \\
\text { al. } 2018\end{array}$ \\
\hline $\begin{array}{l}\text { Partial mitochondrial small subunit } \\
\text { of ribosomal DNA (mtSSU) }\end{array}$ & MS1+MS2 (White et al. 1990) & same as for ITS \\
\hline $\begin{array}{l}\text { Region between domains six and } \\
\text { seven of the nuclear gene encoding } \\
\text { the second largest subunit of RNA } \\
\text { polymerase II }(r p b 2)\end{array}$ & bRPB2-6F+ bRPB2-7.1R (Matheny 2005) & $\begin{array}{l}\text { Cabon̆ et al. } \\
2017\end{array}$ \\
\hline $\begin{array}{l}\text { First largest subunit of RNA } \\
\text { polymerase II }(r p b 1)\end{array}$ & $\begin{array}{l}\text { Af-Russ «GARTGCCCWGGKCATTTYGG»+Cr- } \\
\text { Russ «CYGCAATRTCRTTGTCCATGTA» }(*)\end{array}$ & $\begin{array}{l}\text { Newly designed } \\
\text { for his study }\end{array}$ \\
\hline $\begin{array}{l}\text { Transcription elongation factor 1- } \\
\text { alpha }(t e f-1 \\
\alpha \text { ) }\end{array}$ & $\begin{array}{l}\text { tef1F+tef1R (Morehouse et al. 2003) 983F+1567R } \\
\text { (Rehner \& Buckley 2005) }\end{array}$ & $\begin{array}{l}\text { Morehouse et al. } \\
2003\end{array}$ \\
\hline
\end{tabular}

\section{Phylogenetic analyses}

Sequence data of five partial loci (mitochondrial rDNA small subunit [mitSSU], nuclear rDNA large subunit [nucLSU], RNA polymerase II largest [rpb1] and second largest subunit [rpb2], and translation elongation factor 1-alpha [tef-1 $\alpha]$ ) for collections of $R$. glutinosoides sp. nov., for one specimen of $R$. glutinosa (DMWR 04.1154) and for the holotype of $R$. fattoensis (see Table 2) were added to the alignment presented in Buyck et al. (2018). This combined dataset included 3532 characters after exclusion of ambiguous regions delimited by eye (gap regions in variable parts of the rDNA, spliceosomal introns in protein-coding genes and a highly variable region in $R P B 2$ which is not unambiguously alignable based on amino-acid sequences). Maximum likelihood analyses were conducted on the 168 specimens/5 locus dataset using RAxML-HPC2 8.2.12 (Stamatakis, 2014) on the CIPRES Science Gateway 3.3 (https://www.phylo.org/, Miller et al. 2010) with the same settings as in Buyck et al. (2018): rapid bootstrap algorithm (RBS; option fa; Stamatakis et al. 2008), general time-reversible model (GTR) with the option -m GTRGAMMA and 1000 runs each starting from a distinct heuristic starting tree (option - N 1000). Bootstrap values were estimated based on 500 bootstrap replicates and were considered significant when $\geq$ 70\% (Alfaro et al. 2003).

Sequences of the nuclear rDNA internal transcribed spacers 1 and 2 plus the 5.8S (ITS) were obtained for four collections of $R$. glutinosa, the holotype of $R$. fattoensis and two collections of $R$. glutinosoides sp. nov. These sequences were aligned manually in MacClade v4.05 (Maddison \& Maddison 2002) together with one sequence for $R$. glutinosa previously deposited in GenBank (EU598202; from Buyck 04.202). After exclusion of ambiguously aligned regions (83 characters) the alignment used for phylogenetic analyses included 492 characters. Following the results of our multigene analysis, subgenus Archaeae was chosen as outgroup and ITS sequences sampled among 
GenBank deposits resulting from a previous study (Buyck et al. 2017): KY800355 for $R$. archaeosuberis; KY800353 for $R$. cf. camarophylla; KY800350 for R. gossypina and KY800354 for $R$. pseudoaurantiophylla). Analyses of ITS sequences were conducted on the same server and program (RAxML-HPC2) with the same settings but used 500 runs (option - N 500).

Table 2 Voucher table for newly generated sequences in this study. All other vouchers used in the multi-locus analysis correspond to the voucher table provided in Buyck et al. (2018).

\begin{tabular}{|c|c|c|c|c|c|c|c|c|}
\hline Extr/collector $n r$ & Country & $\begin{array}{l}\text { Herb } \\
\text { barcode }\end{array}$ & ITS & nucLSU & mitSSU & $r p b 1$ & $r p b 2$ & Tef-1 $\alpha$ \\
\hline \multicolumn{9}{|l|}{ Russula fattoensis } \\
\hline $\begin{array}{l}\text { Buyck } 02.227 \\
\text { (type) }\end{array}$ & USA & PC0125084 & $\begin{array}{l}\text { MN31554 } \\
5\end{array}$ & $\begin{array}{l}\text { MN31551 } \\
4\end{array}$ & \begin{tabular}{|l} 
MN31553 \\
7
\end{tabular} & - & \begin{tabular}{|l|} 
MN32679 \\
7
\end{tabular} & $\begin{array}{l}\text { MN32680 } \\
0\end{array}$ \\
\hline \multicolumn{9}{|l|}{ Russula glutinosa } \\
\hline Buyck 04.202 & USA & PC0125107 & $\begin{array}{l}\text { MN31554 } \\
4\end{array}$ & \begin{tabular}{|l} 
MN31551 \\
3
\end{tabular} & \begin{tabular}{|l} 
MN31553 \\
6
\end{tabular} & - & \begin{tabular}{|l} 
MN32679 \\
6 \\
\end{tabular} & - \\
\hline Buyck 04.292 & USA & PC0125108 & $\begin{array}{l}\text { MN31554 } \\
3\end{array}$ & $\begin{array}{l}\text { MN31551 } \\
2\end{array}$ & $\begin{array}{l}\text { MN31553 } \\
5\end{array}$ & - & $\begin{array}{l}\text { MN32679 } \\
5\end{array}$ & - \\
\hline Fatto 798 & USA & $\begin{array}{l}\text { NY0207266 } \\
7 \\
\end{array}$ & $\begin{array}{l}\text { MN31554 } \\
2\end{array}$ & - & \begin{tabular}{|l} 
MN31553 \\
4 \\
\end{tabular} & - & - & - \\
\hline Fatto 1034 (type) & USA & $\begin{array}{l}\text { NY0025350 } \\
7\end{array}$ & $\begin{array}{l}\text { MN31554 } \\
1\end{array}$ & - & $\begin{array}{l}\text { MN31553 } \\
3\end{array}$ & - & - & - \\
\hline $\begin{array}{l}\text { Roody WRWV } \\
04.1154\end{array}$ & USA & $\begin{array}{l}\text { DEWV-F- } \\
005518\end{array}$ & $\begin{array}{l}\text { MN31554 } \\
0\end{array}$ & \begin{tabular}{|l} 
MN31551 \\
1
\end{tabular} & $\begin{array}{l}\text { MN31553 } \\
2\end{array}$ & - & $\begin{array}{l}\text { MN32679 } \\
8\end{array}$ & $\begin{array}{l}\text { MN32679 } \\
9\end{array}$ \\
\hline Fatto 1142 & USA & $\begin{array}{l}\text { NY0207269 } \\
3\end{array}$ & - & - & - & - & - & - \\
\hline Fatto 982 & USA & $\begin{array}{l}\text { NY0067246 } \\
9\end{array}$ & - & - & - & - & - & - \\
\hline \multicolumn{9}{|c|}{ Russula glutinosoides } \\
\hline $\begin{array}{l}\text { XH Wang } 4578 \\
\text { (type) }\end{array}$ & China & $\begin{array}{l}\text { KUN } \\
\text { HKAS, } \\
\text { PC0125109 }\end{array}$ & $\begin{array}{l}\text { MN43418 } \\
7\end{array}$ & \begin{tabular}{|l} 
MN42882 \\
7
\end{tabular} & \begin{tabular}{|l} 
MN46031 \\
3
\end{tabular} & $\begin{array}{l}\text { MN43368 } \\
7\end{array}$ & $\begin{array}{l}\text { MN43368 } \\
5\end{array}$ & $\begin{array}{l}\text { MN43368 } \\
9\end{array}$ \\
\hline LPT 1542 & China & $\begin{array}{l}\text { KUN } \\
\text { HKAS }\end{array}$ & $\begin{array}{l}\text { MN43418 } \\
6\end{array}$ & \begin{tabular}{|l|} 
MN42882 \\
6 \\
\end{tabular} & \begin{tabular}{|l} 
MN46031 \\
4 \\
\end{tabular} & $\begin{array}{l}\text { MN43368 } \\
6\end{array}$ & \begin{tabular}{|l|} 
MN43368 \\
4
\end{tabular} & \begin{tabular}{|l|} 
MN43368 \\
8 \\
\end{tabular} \\
\hline
\end{tabular}

\section{Results}

\section{Phylogeny}

The multilocus analysis (Fig. 1) strongly suggests that $R$. fattoensis is a synonym of $R$. glutinosa and both form a fully supported monophyletic clade (BS=100\%) with the sequenced Chinese specimens. These Asian collections represent a genetically distinct sister species which is here described as $R$. glutinosoides. With high support (BS=96\%), the $R$. glutinosa $-R$. glutinosoides clade is sister to a fully supported monophyletic clade (BS=100\%) composed of subgenera Compactae and Archaeae. The ITS sequences of the holotypes of $R$. fattoensis and $R$. glutinosa and all other American specimens are identical. In the ITS phylogeny (Fig. 2) they formed a fully supported clade (BS=100\%). The two Chinese specimens also share an identical ITS sequence that is $97 \%$ similar to the one of $R$. glutinosa. The phylogenetic analysis of ITS sequences places $R$. glutinosa and $R$. glutinosoides in a strongly supported clade with a long branch that is clearly distinct from other species with similarly small spores (i.e. Russula subg. Archaeae).

\section{Taxonomy}

Considering the phylogenetic results of the multi-locus analyses (Fig. 1), we here describe a new subgenus to contain $R$. glutinosa and $R$. glutinosoides sp. nov.

Russula subgenus Glutinosae Buyck \& X.H. Wang, subg. nov.

MycoBank number: MB 833737 
Diagnosis. The new subgenus shares with Russula subg. Archaeae the hygrophoroid field habit resulting from the unequal, thick and more or less spaced lamellae and the very small spores, but differs in the more reticulate spore ornamentation, darker spore print, presence of septate pileocystidia, the slender hyphal terminations in the pileipellis having frequently inflated apices, and the occurrence of frequent swellings near septa.

Type species - Russula glutinosa Fatto, Mycotaxon 70:170. 1999

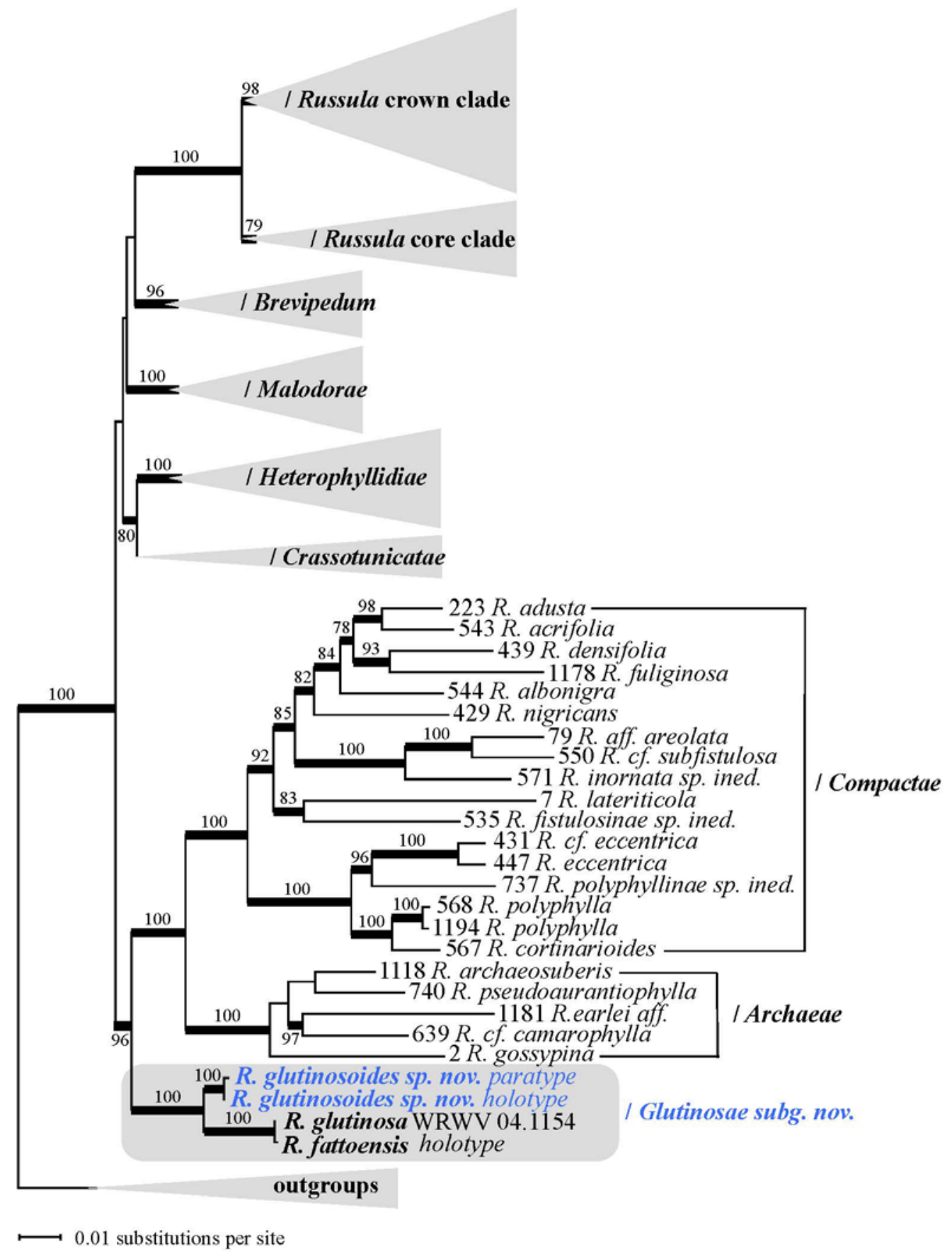

Figure 1 - Most likely tree obtained by ML analysis of the 168 specimens/5 locus dataset (-ln 57423.49377). Branches significantly supported are in bold and bootstrap values indicated along the branches. Newly described taxa are in bold blue font and the new subgenus Glutinosae indicated by the grey rectangle. For details of vouchers see voucher table provided in Buyck et al. (2018). Note the newly introduced orthographic correction for names of accepted subgenera in Russula. 


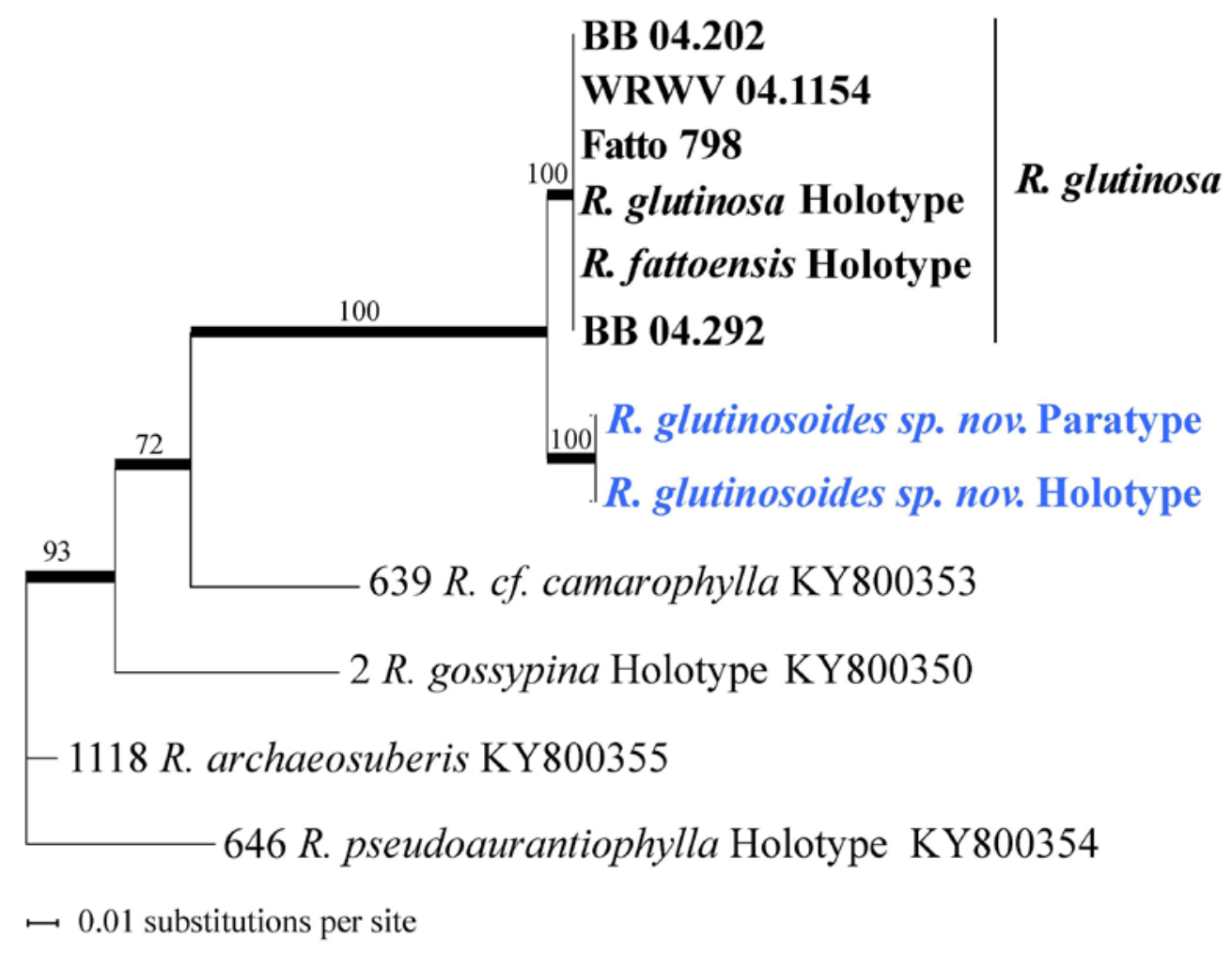

Figure 2 - Most likely tree obtained by ML analysis of the ITS dataset $(-\ln =1319.94811)$. Branches significantly supported are in bold and bootstrap values indicated along the branches. The newly sequenced specimens are in bold and the new species is in bold blue. Voucher information for out-group species is given in Buyck et al. (2018).

For the sake of completeness, we first provide here a full description for the holotype of $R$. fattoensis as this was never published.

Russula fattoensis Buyck, Cryptogamie, Mycologie 25 (2): 181. 2004

Figs 3, 4, 11a-b

\section{Original description}

Pileus usque ad 89 mm diam., regularis, plano-depressus, firmus, carnosus; margo laevis, juventu involutus; pileipellis secernens usque ad 1/4 radii, paulum viscosa, lucens sicco, continua, haud pruinosa, rubro-brunnea sed marginem versus cito pallidior et cremea vel albida. Lamellae adnatae, normaliter dispositae (plus minusve 1/mm), 5-6 $\mathrm{mm}$ altae, haud fragiles, interstitiis venosae, tactu roseo-brunnescentes, lamellulis numerosis saepe brevibus intermixtae; acies concolor, integra. Stipes $46-49 \times 15-23 \mathrm{~mm}$, cylindratus, irregulariter... in parte basale, laevis, albus, griseus basim versus tactu brunnescens, firmus, durus, plenus. Caro alba, mox rubro-brunnea vel brunneo-rosea, stipiti base grisescens, inodora, fortiter interdum tarde acris. Sporae albae in cumulo. Caracteres microscopici R. earlei affines.

Holotypus: America borealis, Nova Caesarea, in sylvis frondosis praecipue fagetis, in herbario PC conservatus sub numero Buyck 02.227.

\section{Type study}

Pileus up to $89 \mathrm{~mm}$ in diam., quite regular in outline, slightly depressed to plane in the center, firm and quite thick (11-12 mm above lamellar attachment); margin smooth, involute when young; cuticle shortly peeling (up to $1 / 4$ of the radius), slightly viscose when humid, shiny when dry, not pruinose, smooth and continuous, occasionally fissuring from drought, warm reddish brown 
(5DE7-8 in the center, becoming rapidly much paler (5C5-7), cream (4A2-4) to whitish toward the margin. Lamellae unequal with many lamellulae of different lengths, especially many short ones, adnate, moderately spaced (approx. $1 \mathrm{~L}+\mathrm{l} / \mathrm{mm}$ near the pileus margin), 5-6 mm high, thick, often splitting transversely, not easily breaking when touched, strongly anastomosing between lamellae near the pileus context, not forked near the stipe attachment, but occasionally so closer to the pileus margin, cream and staining brownish pink where injured or upon handling; edge even, concolorous. Spore producing surface abruptly delimited from the sterile stipe surface. Stipe 46-49 × 15-23 mm, central, cylindrical but narrowing and irregularly wrinkled-deformed at the base, smooth, glabrous, chalky white, greyish near the base and browning from injuries, firm and very hard, massive and without cavities. Context white, but quickly reddish brown to brownish pink when cut, distinctly grey in the stipe lower half, certainly in young specimens. Odour weak, not unpleasant. Taste very acrid, typically after a few seconds. Spore print first seemingly white, warm cream [II(b-)c code Romagnesi] when scraped together. Exsiccatum yellowish brown, shiny, darker at the center.

Spores broadly ellipsoid to ellipsoid, (4.8-)4.9-5.3-5.6(-6.1) $\times(3.5-) 3.7-3.9-4.2(-4.5) \mu \mathrm{m}$, $\mathrm{Q}=(1.25-) 1.28-1.34-1.4(-1.47)$; ornamentation low, subreticulate, composed of numerous [(8-)912(-13) warts in a $3 \mu \mathrm{m}$ diam. circle on spore surface], moderately amyloid, obtuse warts [(8-)912(-13) warts in a $3 \mu \mathrm{m}$ diam. circle on spore surface], $0.1-0.2 \mu \mathrm{m}$ high, connected by numerous fine line connections [3-5(-7) in the circle] or frequently fused in pairs or short chains [(1-)3-6(7) fusions in the circle]; suprahilar spot inamyloid, inconspicuous, small. Basidia (32-)37.5-41.545.5(-50) × 5.5-6-7(-7.5) $\mu \mathrm{m}$, 4-spored, narrowly clavate to subcylindrical; basidiola first cylindrical, then narrowly clavate. Hymenial gloeocystidia very abundant on lamellar sides, ca. 5500-7500 per $\mathrm{mm}^{2}$, (34-)42-56.5-71(-84) $\times$ 4.5-5.5-6(-7) $\mu \mathrm{m}$, narrowly clavate to subcylindrical, with obtuse tips, occasionally apically slightly constricted, thin-walled, without appendage, not mucronate, for the larger part filled with heteromorphous (granular or crystalline) contents that are moderately graying in sulfovanilin; at the lamellar edge more dispersed and usually shorter, (16-)22.5-28.5-34(-40) $\times$ 4-4.5-5(-5.5) $\mu \mathrm{m}$, with less abundant contents. Marginal cells occupying most of the lamellar edges, (10-)12.5-16-19(-22) × 3-4-4.5(-5) $\mu \mathrm{m}$, similar in shape to basidioles but smaller, cylindrical or narrowly clavate, often slightly moniliform, obtuse-rounded at the tips. Subhymenium pseudoparenchymatic. Lamellar trama containing of sphaerocytes. Pileipellis orthochromatic in Cresyl blue, not sharply delimited from the underlying sphaerocytes of the context, ca. 220-230 $\mu \mathrm{m}$ deep; vaguely two-layered. Suprapellis ca. 120-150 $\mu \mathrm{m}$ deep, composed of erect, rarely branched, strongly gelatinized and relatively dense hyphal endings composed of very few cells. Subpellis very dense, pseudoparenchymatic, less gelatinized, ca. 90-110 $\mu \mathrm{m}$ thick, composed of 4-15 $\mu \mathrm{m}$ wide hyphae. Acidoresistant incrustations absent. Terminal cells near the pileus margin (17-)24-35-45.5(-61) $\times(3-) 3.5-4-5(-6) \mu \mathrm{m}$, cylindrical, apically obtuse and usually distinctly inflated to capitate, rarely constricted, also near basal septum often swollen; subterminal cells usually not branched, distinctly inflated near the proximal septum and there 5-9 $\mu \mathrm{m}$ wide. Terminal cells at the pileus center similar to those near the margin but more distinctly capitate, $(25-) 28.5-40-52(-83) \times(3.5-) 4-5-5.5(-6.5) \mu \mathrm{m}$; subterminal cells more often branched, usually inflated near the proximal septum. Pileocystidia near the pileus margin 1(2-3)-celled, subcylindrical, apically obtuse or rarely constricted, straight or occasionally flexuous, thin-walled, (29-)30-62-93(>150) $\times$ 3.5-4.5-5.5(-6.5) $\mu \mathrm{m}$, some very long and originating deep in the trama, contents in Congo red in major part heteromorphic granulose or banded, weakly reacting in sulfovanilin, yellow-green in Cresyl blue. Pileocystidia at the pileus center smaller, cylindrical, often flexuous and apically mucronate or with small capitulum, measuring ca. $27-82 \times 3-5 \mu \mathrm{m}$, optically empty or with poor heteromorphic contents, at their surface bearing a yellow incrustation that does not react to any reagents. Cystidioid hyphae present in subpellis, in particular just above the pileus context, also continuing deeper in pileus and lamellar trama, mostly septate and bearing the same yellow incrustations, turning brownish grey in sulfovanillin. Clamp connections absent in all parts. 


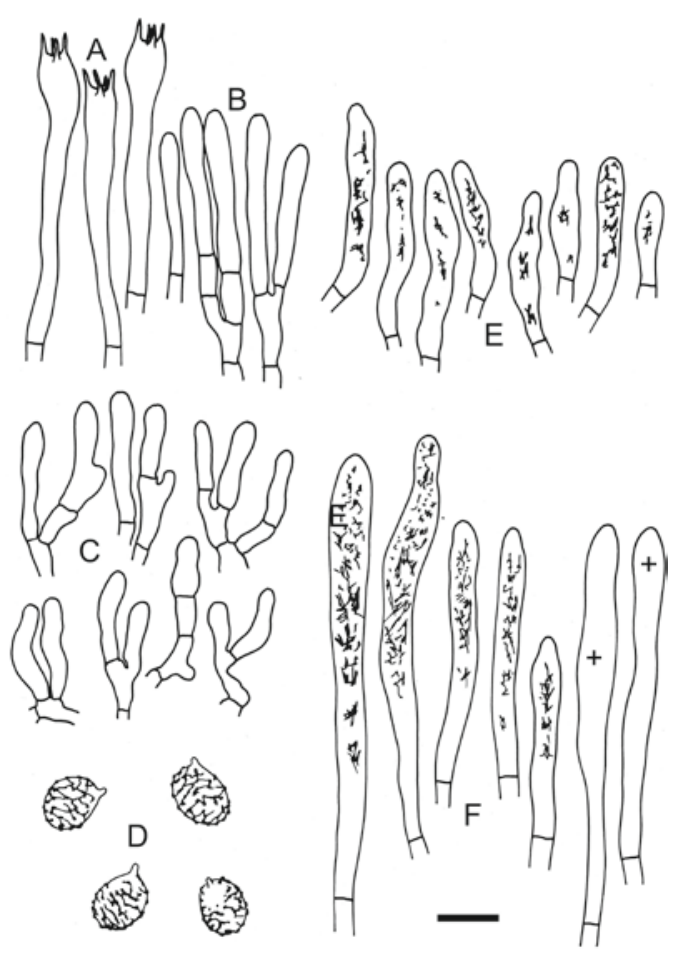

Figure 3 - Russula fattoensis (holotype). Microscopic features of the hymenium. A Basidia. B Basidiola. C Marginal cells on the lamellar edges. D Spores. E Hymenial gloeocystidia near the lamellar edges. F Hymenial gloeocystidia on the lamellar sides. Cystidia with contents as observed in Congo Red, some elements with contents indicated schematically by a plus sign $(+)$. Scale bars $=$ $5 \mu \mathrm{m}$ for spores and $10 \mu \mathrm{m}$ for all other elements. Drawings S. Jančovičová and S. Adamčík.

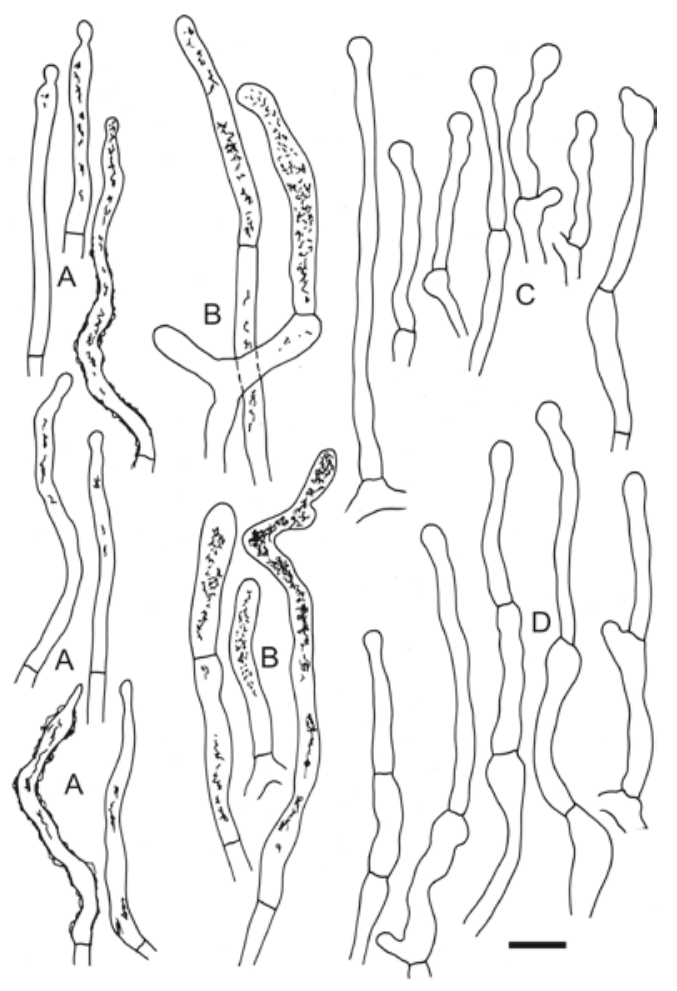

Figure 4 - Russula fattoensis (holotype). Microscopic features of the pileipellis. A Pileocystidia near the pileus center. B Pileocystidia near the pileus margin. C Hyphal terminations near the pileus center. D Hyphal terminations near the pileus margin. Cystidial contents as observed in Congo Red. Scale bars $=10 \mu \mathrm{m}$. Drawings S. Jančovičová and S. Adamčík. 


\section{Original diagnosis}

Pileus 6-9 cm latus, convexus, maturans ad plano-depressum; margo aequus; cutis glutinosa, resiliens, separabilis usque ad 1/3 partem radii, albida ad pallide ochraceam, media cutis leviter luteo-fusca; trama dura, immutans. Lamellae adnatae, subdistantes, cum abundantibus lamellulis, cremeis, immutantibus, sapor acer. Stipes ad 6 x $2 \mathrm{~cm}$, cremeus, glaber, firmus, immutans. Sporae cremeae (Romagnesi IIc), 5-7 x 4-5 $\mu \mathrm{m}$, flocculae $0.1 \mu \mathrm{m}$ altae, segregatae aut cum paucis gracilibus connectivis. Cystidia hymenialia 60-85 x 4-6 $\mu \mathrm{m}$, abundantia, completa granulis reflexisgriseolis. Pileus cutis ad $300 \mu \mathrm{m}$ crassam, desidens in matrice gelatinosa, extendens usque ad 280 $\mu \mathrm{m}$ supra extremas hyphae; pileus subcutis habens hyphas libratas-contextas 2-4 $\mu \mathrm{m}$ latas; pileus epicutis habens trichodermis hypharum hyalinarum 2-4 $\mu \mathrm{m}$ lata, sine pileocystidiis. Hyphae stipitis cuticis similes cutici pilei, sed cum multis oleiferis extremis hyphis 3-5 $\mu \mathrm{m}$ latis cum reflexogriseolo contento.

Holotypus: Lectus a R.M. Fatto 1034, in Mendham town park, Morris County, New Jersey, USA. 6 August 1997. Conservatus in herbario New York Botanical Garden (NY).

\section{Type study}

Spores ellipsoid, (5.0-)5.2- $\underline{5.5}-5.8(-6.2) \times(3.6-) 3.7-\underline{4}-4.2(-4.3) \mu \mathrm{m}, \mathrm{Q}=(1.25-) 1.33-\underline{1.39}-$ 1.46(-1.5); ornamentation subreticulate, composed of $0.1(-0.2) \mu \mathrm{m}$ high, amyloid warts [(8-)911(-12) warts in a $3 \mu \mathrm{m}$ diam. circle on the spore surface], connected by numerous fine line connections [(2-)3-6(-7) line connections in the circle] and frequently also fused in pairs or short chains [(1-)2-5(-7) fusions in the circle]; suprahilar plage inamyloid, smooth, small and illdefined. Basidia (39-)42-46-51(-53) × (4.5-)5-6-6.5(-7.5) $\mu \mathrm{m}$, 4-spored, narrowly clavate to subcylindrical; basidiola first cylindrical, then narrowly clavate. Subhymenium narrowly pseudoparenchymatic. Lamellar trama with sphaerocytes. Hymenial gloeocystidia on lamellar sides numerous, ca. 2000-3000 per $\mathrm{mm}^{2}$, (57-)65-80-95(-112) × (4.5-)5-5.5-6 $\mu \mathrm{m}$, narrowly clavate, narrowly fusiform to subcylindrical, with mostly acute tips, often apically prolonged with a 3-8 $\mu \mathrm{m}$ long appendage, containing granular or crystalline contents that react weakly in sulfovanillin; at the lamellar edge dispersed, similar but usually shorter, (31-)41.5-51-60(-65) × 4.5-5.5-6(-7) $\mu \mathrm{m}$. Marginal cells very abundant, in shape similar to basidioles but smaller, cylindrical or narrowly clavate, obtuse, often slightly moniliform, measuring (10-)13.5-18-22.5(-24) × 3-3.8-4.5(-5) $\mu \mathrm{m}$. Pileipellis orthochromatic in Cresyl blue, not sharply delimited from the underlying context, ca. 180-210 $\mu \mathrm{m}$ deep, vaguely divided in ca. 50-70 $\mu \mathrm{m}$ deep suprapellis of erect or ascending, sometimes basally branched, strongly gelatinized and narrow hyphal endings, and a very dense, less gelatinized, ca. 130-150 $\mu \mathrm{m}$ deep subpellis of 3-8 $\mu \mathrm{m}$ wide, intricate hyphae that become gradually more horizontally oriented towards pileus context, often more or less strongly inflated near septa. Hyphal terminations composed of 2-4 subcylindrical cells, narrow except sometimes near septa; terminal cells near the pileus margin measuring $(12-) 15-20-25.5(-34) \times 2.5-3.5-4(-5) \mu \mathrm{m}$, cylindrical, the very tip obtuse and frequently inflated to almost capitate; terminal cells near the pileus center longer than those near the margin, often subcapitate or occasionally distinctly capitate, measuring (17-)24-35-46.5(-65) × (2-)2.5-3-4(-5) $\mu \mathrm{m}$; subterminal cells mostly unbranched, usually shorter, often distinctly inflated near the proximal septum. Pileocystidia near the pileus margin inconspicuous, thin-walled, small, narrow, (1-)2-3-celled, subulate to subcylindrical, apically attenuated or mucronate, straight or slightly flexuous; terminal cells (15-)18.5-25-31(-37) $\times 2-2.5-3(-3.5) \mu \mathrm{m}$, mostly optically empty in Congo red, but some with few inclusions or in apical part yellowish and refringent, insensitive to sulfovanillin, in more basal parts encrusted with yellow incrustations that stain yellow-green in Cresyl blue, and red after karbolfuchsin treatment; those in the pileus center similar but with narrower and longer terminal cells, measuring (1.5)18.5-31-43(-70) × (1.5-)2-2.5-3(-3.5) $\mu \mathrm{m}$, apically attenuated and usually mucronate, with similar contents and incrustations as those near margin. Cystidioid hyphae in subpellis and trama 
present, dispersed, with more conspicuous, distinctly heteromorphous contents in Congo red. Clamp connections absent in all parts.

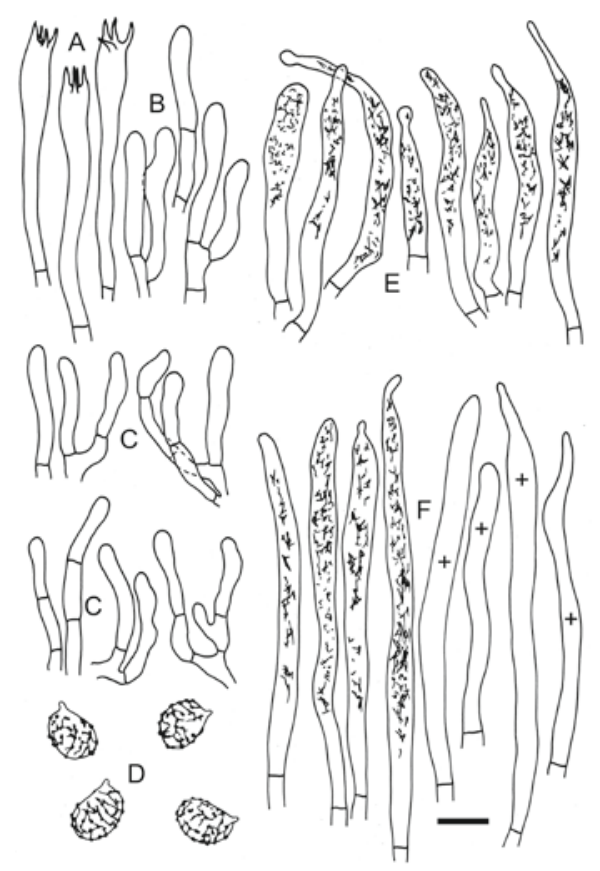

Figure 5 - Russula glutinosa (holotype). Microscopic features of the hymenium. A Basidia. B Basidiola. C Marginal cells on the lamellar edges. D Spores. E Hymenial cystidia on the lamellar edges. F Hymenial cystidia on the lamellar sides. Cystidia with contents as observed in Congo Red, some elements with contents indicated schematically by a plus sign $(+) .-$ Scale bar equals $5 \mu \mathrm{m}$ for spores and $10 \mu \mathrm{m}$ for all other elements. Drawings S. Jančovičová and S. Adamčík.

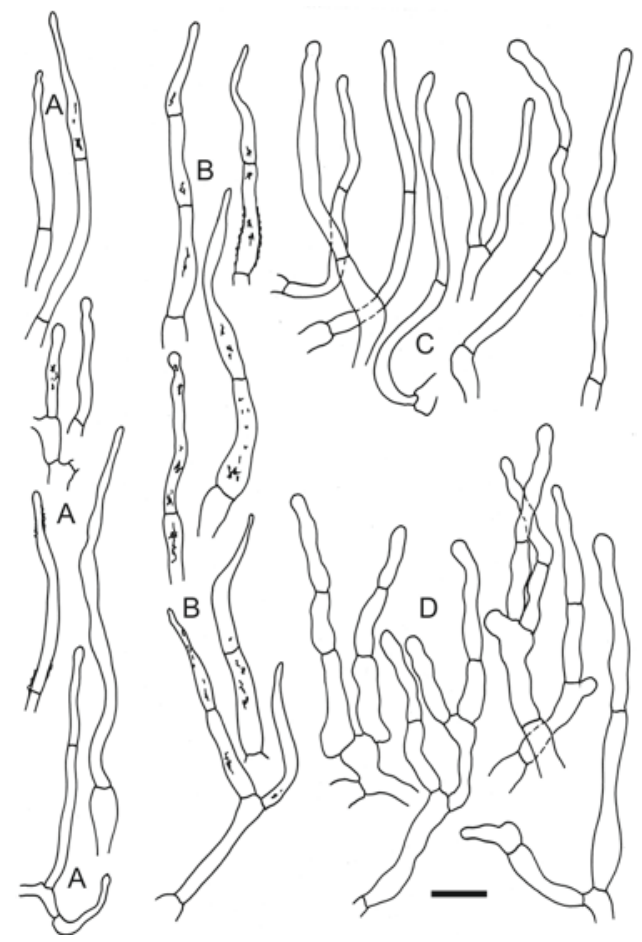

Figure 6 - Russula glutinosa (holotype). Microscopic features of the pileipellis. A Pileocystidia near the pileus center. B Pileocystidia near the pileus margin. C Hyphal terminations near the pileus center. D Hyphal terminations near the pileus margin. Cystidial contents as observed in Congo Red. Scale bar $=10 \mu \mathrm{m}$. Drawings by S. Jančovičová and S. Adamčík. 


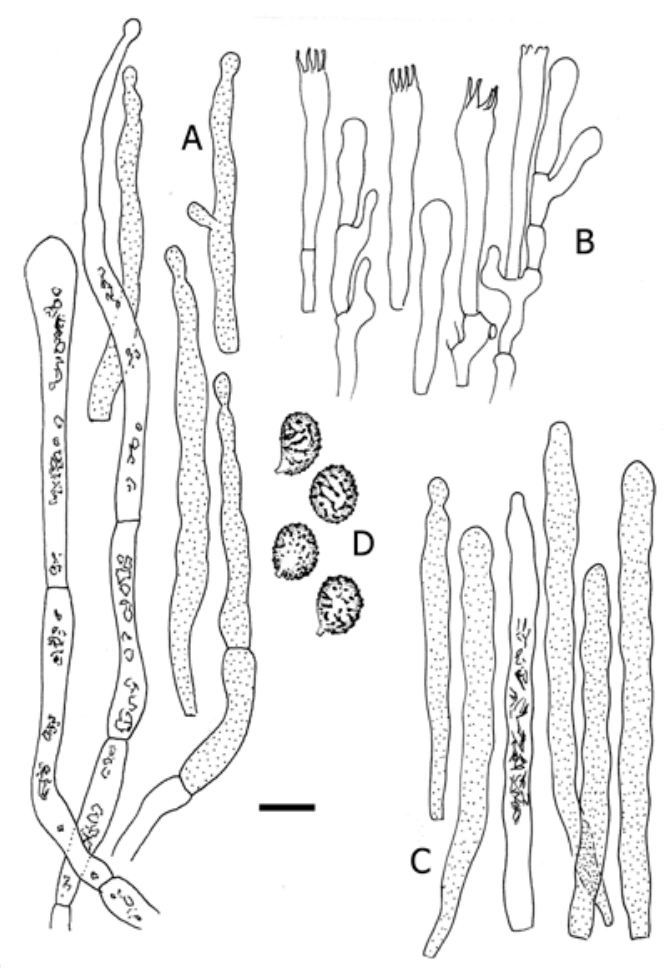

Figure 7 - Russula glutinosa. Microscopic features (WRWV 04.1154). A. Pileocystidia near the pileus margin. B. Basidia and basidiola. C. Hymenial gloeocystidia. D. Basidiospores as observed in Melzer's reagent. Scale bars $=5 \mu \mathrm{m}$ for spores, $10 \mu \mathrm{m}$ for all other elements. Drawings B. Buyck.

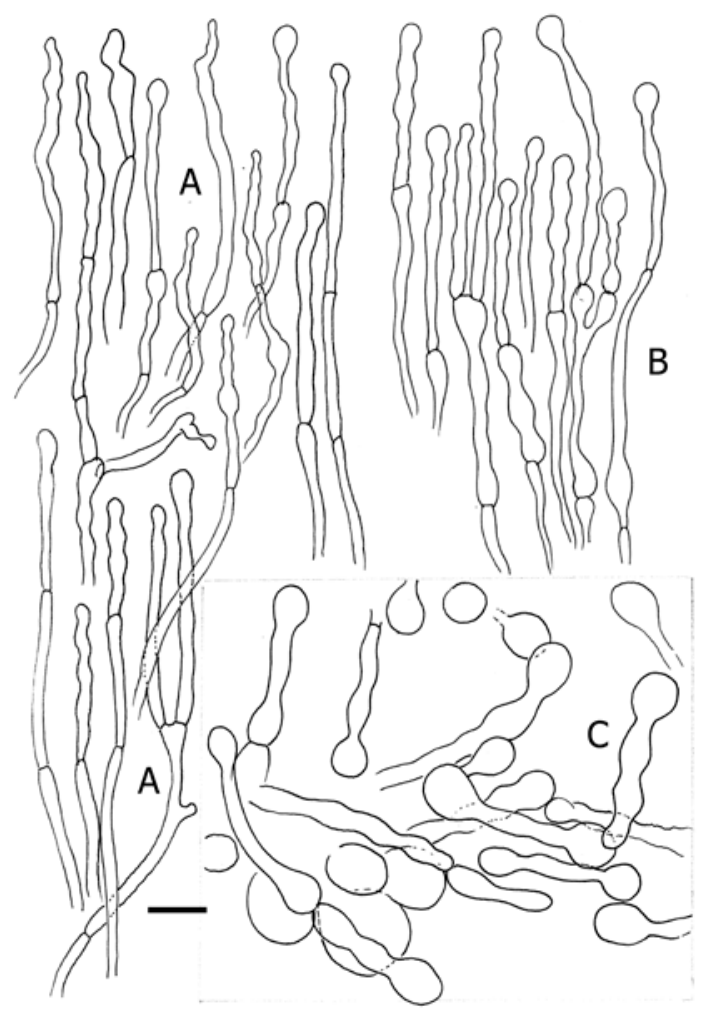

Figure 8 - Russula glutinosa. Microscopic features of the pileipellis (WRWV 04.1154). A. Hyphal terminations of the pileus center. B. Hyphal terminations near the pileus margin. C. Surface view of the pileipellis near the pileus margin showing the inflated terminal cells of hyphal terminations and the inflations near septa at their base. Scale bar $=10 \mu \mathrm{m}$. Drawings B. Buyck. 
Material examined - UNITED STATES OF AMERICA. New Jersey, MorRIS Co., Meadow woods, in mixed broadleaf forest, 15 July 2002; Buyck 02.227 (PC0125084, holotype of $R$. fattoensis); ibid., 10 July 1994, R. M. Fatto 798 (NY02072667), ibid., Mendham town park, in mixed deciduous forest with Quercus and Fagus, 6 August 1997, R. M. Fatto 1034 (holotype, NY00253507); ibid., 2 Aug. 1998, R. M. Fatto 1142 (NY02072693); New York, OrANGE Co., Greenwood Lake, Jennings Creek, 210 m alt., under Tsuga, 28 July 1996, A. Norarevian coll., R.M. Fatto 982 (NY00672469); North Carolina: BunCOMBE Co, near Asheville, NAMA Foray, 17 July 2004, B. Buyck 04-292 (PC0125108); West-Virginia: RALEIGH Co., Grandview Park, near Quercus alba, Pinus strobus and Rhododendron maximum, 732 m alt., 2 Sept. 2004, William Roody WRWV 04-1154 (DEWV-F-005518). Tennessee. SEVIER Co., Great Smoky Mts National Park, Vicinity Gatlinburg, 2450 m alt., in mixed forest with Tsuga, Quercus, 12 July 2004, B. Buyck 04.202 (PC0125107)

Russula glutinosoides Buyck \& X.H. Wang, sp. nov.

Mycobank number: MB 833738; Facesoffungi Number: FoF 07372

Etymology - named after its resemblance to $R$. glutinosa

Differs from $R$. glutinosa principally by sequence data and its geographical distribution which is limited to China or possibly larger parts of Asia; morphologically it differs by the more frequently septate and larger pileocystidia, particularly closer to the pileus context.

Basidiomata single or in very small groups of 2-3 individuals, medium-sized. Pileus $97 \mathrm{~mm}$ diam., quite regular in outline, slightly depressed to plane in the center, firm and quite thick (9 mm above lamellar attachment); margin smooth, rounded and oriented downward, involute when young; pellis peeling up to mid-radius, viscous-greasy when humid, shiny when dry, not pruinose, smooth and continuous, rather evenly coloured over its entire surface, creamish to pale yellow. Lamellae unequal, multiseriate, being separated by 0-3 lamellulae of different lengths, especially many very short ones, adnate, rather widely spaced (7-8/cm near the pileus margin), $8 \mathrm{~mm}$ high, brittle, some splitting transversely, narrowing toward the pileus margin, not or rarely forked at various distances from stipe, sharply delimited from the sterile stipe surface, cream, staining weakly brownish pink where injured or upon handling; edge even, concolorous. Stipe $48 \times 23 \mathrm{~mm}$, central, gradually narrowing downward, smooth, glabrous, probably white when young, but yellowish tinged (possibly from handling), very firm and hard, hollowed in the very center (possibly by animal attack). Context whitish, turning quickly reddish brown to brownish pink where injured. Odor not remarkable. Taste acrid, but not very strong. Spore print colour not observed.

Spores very small, ellipsoid to almost lacryform, (4.5)5.0-5.29-5.6(5.8) × (3.3)3.4-3.663.8(4.0) um, $\mathrm{Q}=$ (1.35)1.38-1.45-1.52(1.56), with a very low, weakly amyloid ornamentation made of obtuse, isolated or often aligned, sometimes irregular or comma-shaped warts, interconnected or fused in short crests, sometimes almost subreticulate; suprahilar plage indistinct, warted, inamyloid. Basidia 31-43 × 5-6 $\mu \mathrm{m}$, narrowly clavate, four-spored, sterigmata 4-5.5 × 1 $\mu \mathrm{m}$. Hymenial gloeocystidia abundant, 63-88 $\times 5-6.5 \mu \mathrm{m}$, narrowly clavate to subcylindrical, often repeatedly but slightly constricted, sometimes with distinctly more inflated apical part, hardly emerging, originating from the trama or lower subhymenium, thin-walled; contents moderately abundant, granular to finely crystalline. Marginal cells small to very small, similar to basidiola or more irregular in shape, occupying the entire lamellar edge. Subhymenium filamentous to densely pseudoparenchymatous. Lamellar trama containing oleiferous elements, with numerous sphaerocytes. Pileipellis in young specimens 200-300 $\mu \mathrm{m}$ thick, orthochromatic to moderately metachromatic in cresyl blue, vaguely two-layered with a suprapellis consisting of a gelatinous layer of almost vertical, narrow hyphal terminations, ascending from an ill-defined layer of more inflated and branching basal cells that may locally develop into a pseudoparenchyma. Hyphal terminations at the pileus center very slender and narrow, ca. $2 \mu \mathrm{m}$ wide, often with distinctly inflated to subglobose, 4-6 $\mu \mathrm{m}$ diam. swellings near the septa or at the very apex, sparsely septate or branched, with the terminations aligned in a continuous trichoderm, becoming more dispersed 
with age and toward the pileus margin, where hyphal terminations are usually shorter and slightly broader, sometimes with more and larger, often repeatedly constricted or globose swellings on short extremities aggregated in tufts. Pileocystidia of very variable length (from hardly $20 \mu \mathrm{m}$ up to several hundreds of $\mu \mathrm{m}$ ), mostly 4-10(15) $\mu \mathrm{m}$ diam., difficult to observe unless close to the pileus margin, dispersed and with sometimes very few contents, some terminal at the very pileus surface, mostly arising from subpellis or deeper layers, often capitate or with otherwise differentiated apex, some one-celled, but most being repeatedly septate, subcylindrical, with granular-amorphous, refringent contents that hardly react to sulfovanillin, orthochromatic in Cresyl blue, showing distinctly incrusted walls away from the apex; the incrustations yellowish in $\mathrm{KOH}$; continuing as cystidioid hyphae in subpellis and pileus context underneath. Oleiferous elements present in context, particular just underneath the subpellis. Clamp connections absent from all parts.

Material examined - China. Yunnan Prov., Nanhua Co., Tujie Town, road from Shuimofang to Lantanhe, km 9 mark, in mixed forest with Pinus yunnanensis and Quercus trees, 15 Aug 2017, X.H. Wang 4578/B. Buyck 2017.131 (HKAS 106678, KUN, holotype!; PC0125109, isotype!); Binchuan Co., Jizushan Town, near Siqian village, 10 Aug. 2011, L.P. Tang 1542 (HKAS 70003, KUN).

\section{Discussion}

Whereas subg. Archaeae has frequently been considered as best potential candidate for most ancient lineage in the genus, subg. Glutinosae now appears a good candidate for an even more ancient lineage compared to subg. Archaea as it is sister with high support to a clade composed of subg. Compactae and Archaeae. The first author has always defended the hypothesis of an origin of Russula in the tropics, possibly in Africa (Buyck et al. 2018), but the apparently Asian-eastern North American distribution of subg. Glutinosae now adds support to an alternative hypothesis suggesting a northern temperate origin of the genus (Looney et al. 2016). Indeed, the new subg. Glutinosae shares its northern hemisphere distribution with subg. Crassotunicatae Buyck \& V. Hofst., another extremely small and isolated lineage that is also present in Europe and phylogenetically sister to subg. Heterophyllidiae.

How to morphologically distinguish between the two species that compose this new subgenus is a serious problem considering there are very few specimens known for each species. Several macroscopic features, such as stipe dimensions or color of pileus center, seem quite variable and, under the microscope, we found no significant differences either. Spore ornamentation seems to be identical for both species, but the holotype of $R$. glutinosoides has somewhat larger and more frequently septate pileocystidia compared to the American $R$. glutinosa. In both species, these gloeocystidia are unusual in having yellowish incrustations on their surface. Although not rare at all, neither at the pileus surface nor in the subpellis or pileus context underneath, they are easily overlooked because they have very thin walls and poorly differentiated contents that hardly react to reagents; moreover, they break easily when making preparations and, although their apex is often capitate, so are most terminations of the other hyphae at the surface.

Both $R$. glutinosa and $R$. glutinosoides are evidently extremely rare or at least totally ignored species and not easy to recognize in the field as the similarity with other genera, in particular from family Hygrophoraceae, can be quite confusing. There exist, for example, no records for either species in Mushroom Observer (https://mushroomobserver.org), while $R$. glutinosa accounts for merely three entries in Mycoportal (http://mycoportal.org/portal/collections), all three being confirmed here molecularly: one for the $R$. glutinosa holotype collected in Mendham town (Morris Co, NJ), one for another R. glutinosa collection studied by R. Fatto from Jennings Creek (Orange Co, NY), and finally a third specimen from Grandview (Raleigh Co, WV). The present paper has raised the total number of known collections for $R$. glutinosa to eight.

We tried to find additional distribution data for subg. Glutinosae by including environmental sequences when doing nBLAST similarity searches on GenBank and in UNITE with the ITS of the Chinese $R$. glutinosoides. The top hit (arranged by max score) is a $97.31 \%$ identity with $99 \%$ coverage for the single already deposited sequence of $R$. glutinosa. 


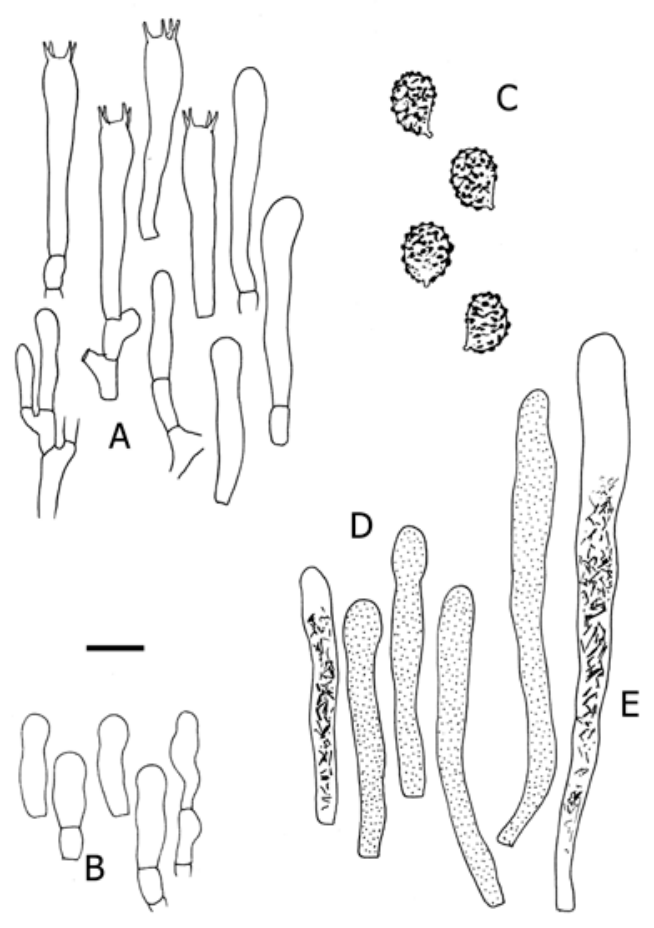

Figure $9-R$. glutinosoides. Microscopic features of the hymenium (Holotype). a Basidia and basidiola. b Marginal cells. c Spores as observed in Melzer's reagent. d Hymenial gloeocystidia on lamellar edge. e Hymenial gloeocystidia on lamellar sides. Scale bars $=10 \mu \mathrm{m}$, but only $5 \mu \mathrm{m}$ for spores. Drawings by B. Buyck.

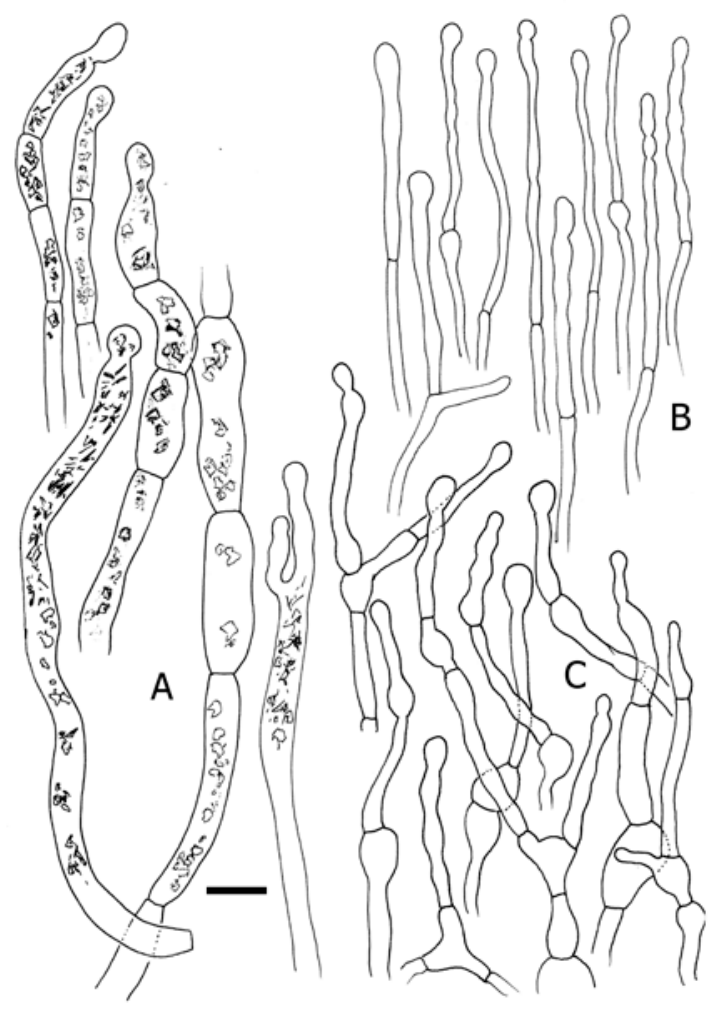

Figure 10 - R. glutinosoides. Microscopic features of the pileipellis (Holotype). a Pileocystidia. b Hyphal extremities of the pileus center. c Hyphal extremities of the pileus margin. Scale bar $=10$ $\mu \mathrm{m}$. Drawings B. Buyck. 

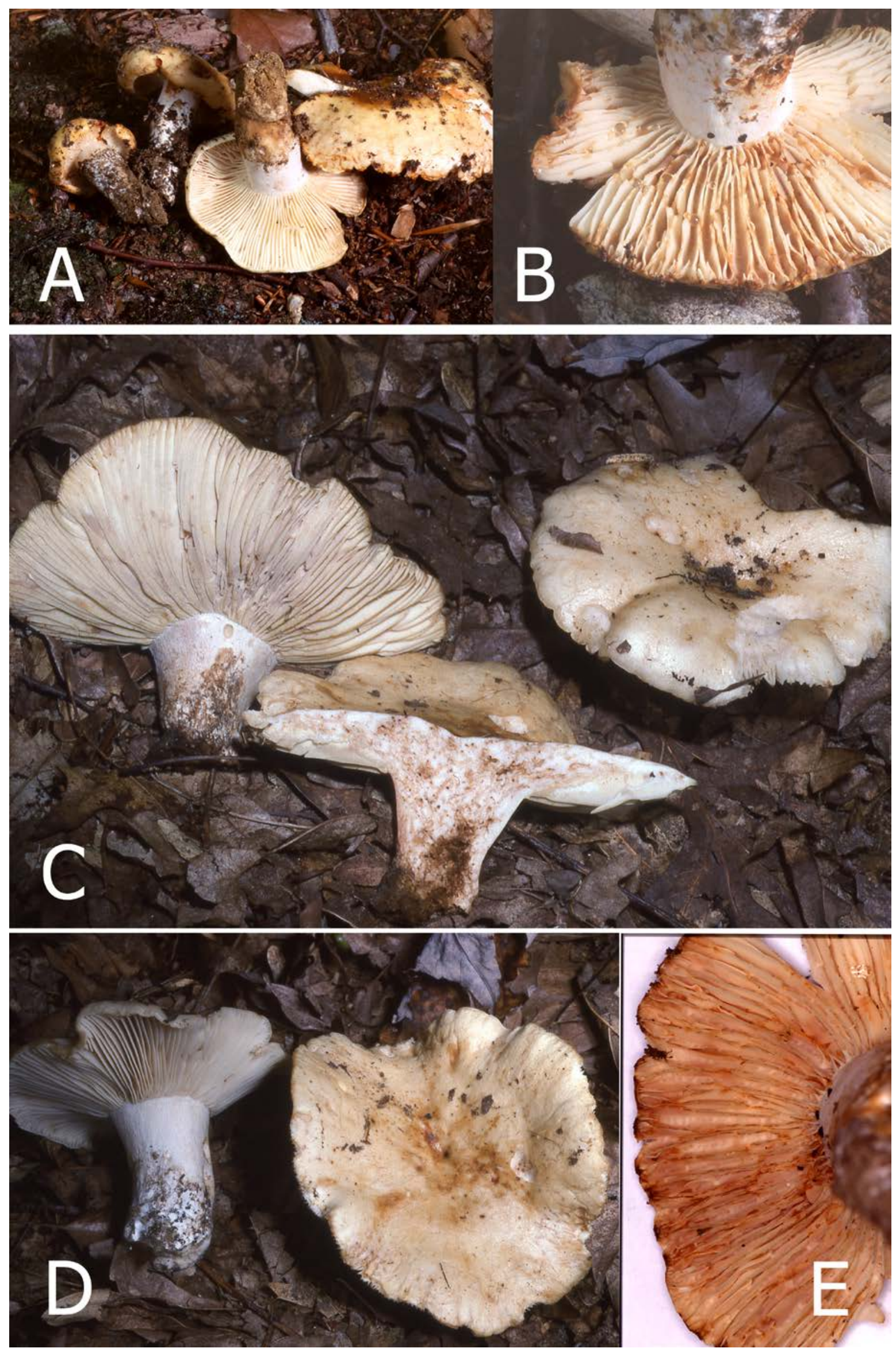

Figure 11 - Russula glutinosa. Field habit. A, B Holotype of R. fattoensis; C, D voucher WRWV 04.1154; E voucher Buyck 04.292 - Pictures copyright of B. Buyck for A, B, E and W. Roody for C, D 

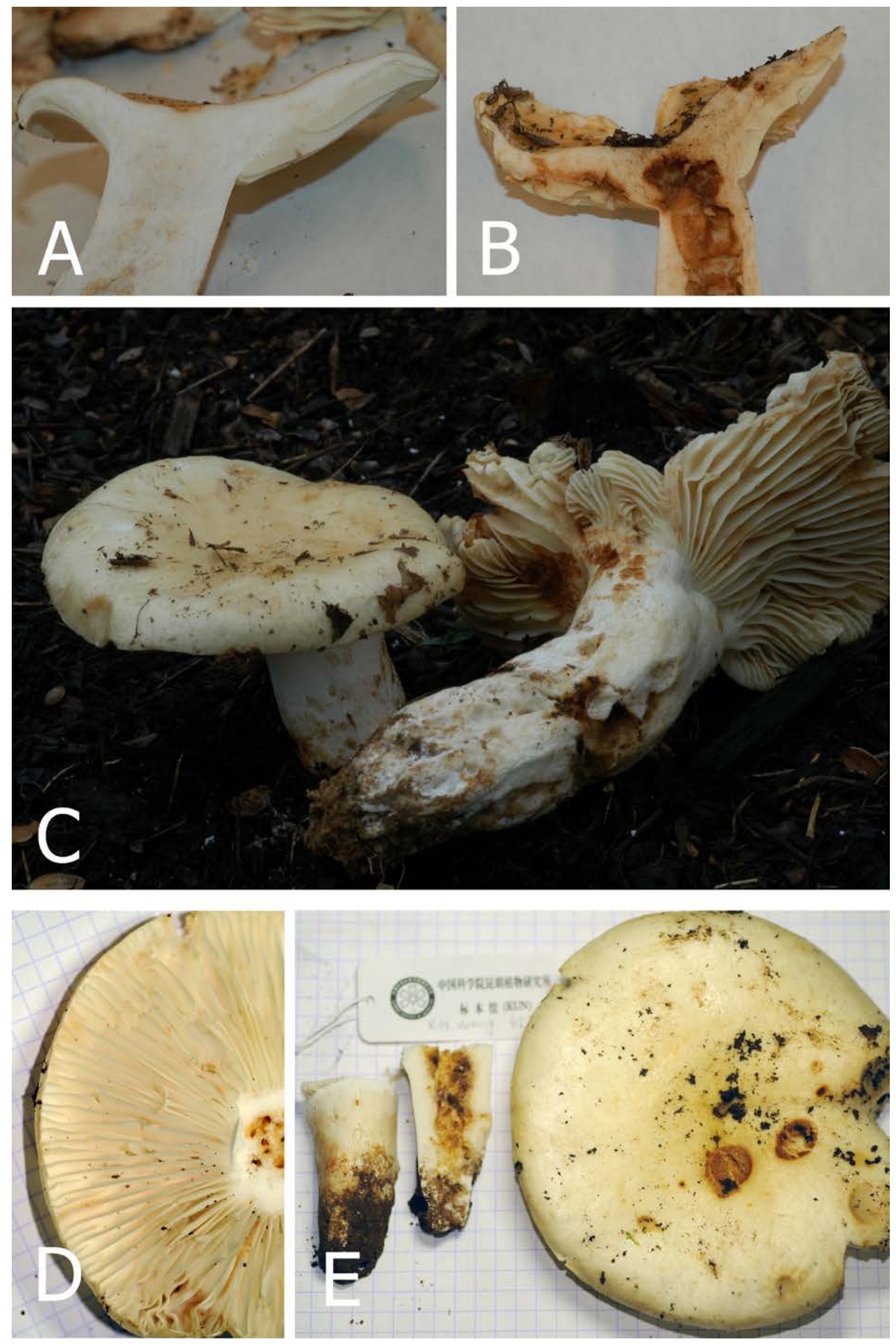

Figure 12 - A, B, C Field habit of Russula glutinosa (Buyck 04.202). D, E R. glutinosoides. (holotype). Photos B. Buyck 


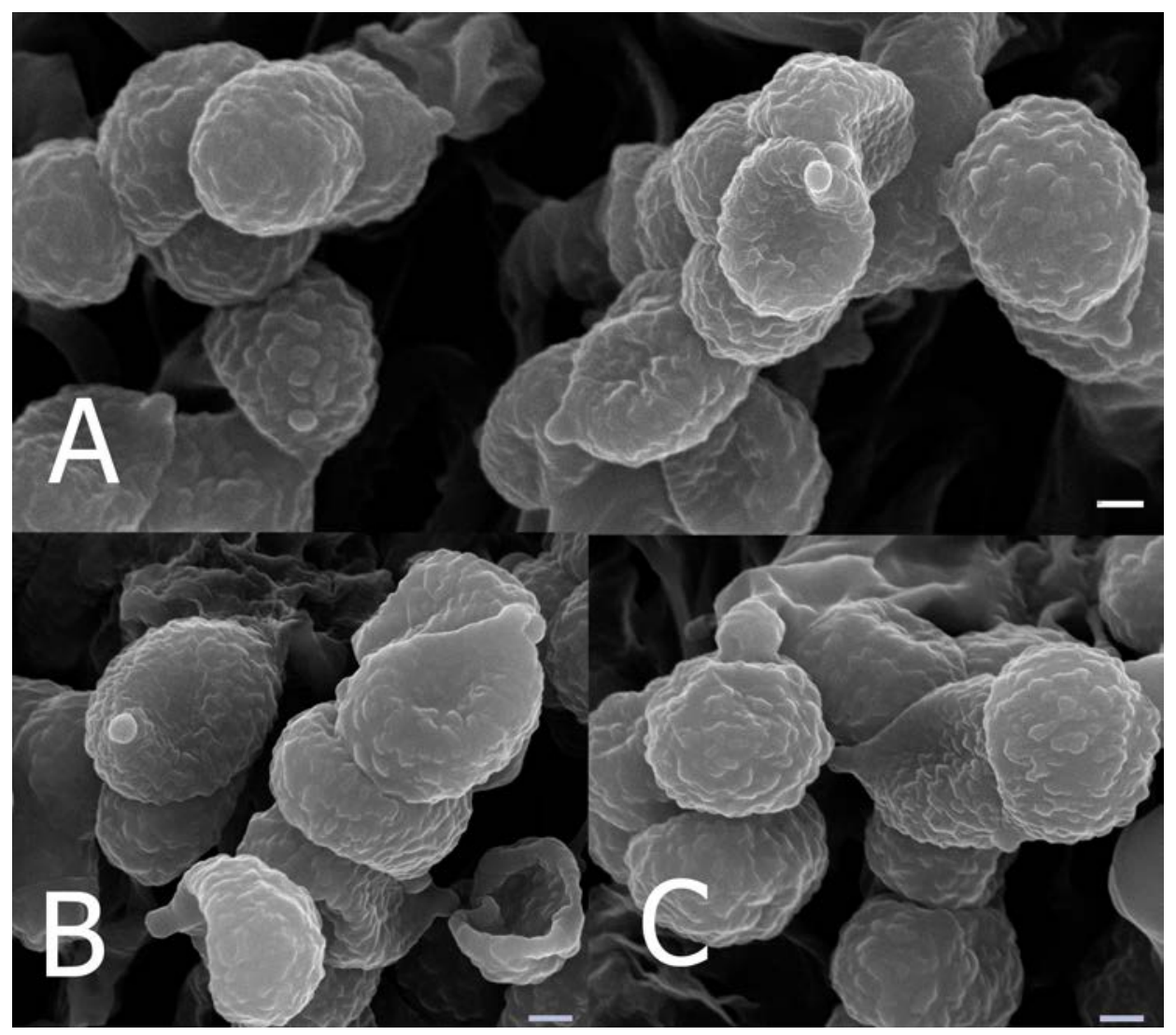

Figure 13 - Spore ornamentation as seen under Scanning Electron Microscope. A R. glutinosoides (holotype). B, C R. glutinosa (BB 04.202). Scale bars $=1 \mu \mathrm{m}$.

The second top hit, however, shows a 98,56\% identity with 93\% coverage for an environmental sequence (AB594932) for a Russula associated with the mycoheterotroph Monotropastrum humile (Ericaceae) in Japan (Matsuda et al. 2011). None of the other ITS sequences is more similar than 86\% (with query coverage between 99 and 90\%). Blasting the ITS of the American $R$. glutinosa results in a single significant hit, on the same environmental sequence, with a similarity of $96.08 \%$ (with a similar 93\% coverage), suggesting that the Japanese sequence represents a close relative or local population of $R$. glutinosoides. Compared to the often numerous environmental sequences present in GenBank for most of the other newly described Russula species (Wang et al. 2019a, Adamčík et al. 2019), these BLAST results suggest that both species are not only rarely producing basidiomes, but also rare below the soil surface. This suggests that both species should be highly ranked on some kind of red list of 'endangered' species of great phylogenetic interest. In this context, more data are urgently needed concerning their host association and ecology as, for the moment, collected fruiting bodies come from 'mixed woods' and potential host trees include both conifers (pine and hemlock) and deciduous trees (oak and beech).

When trying to find morphological similarities between subg. Glutinosae and other subgenera in Russula, the first subgenus that comes to mind is of course subg. Archaeae because of the similarly small basidiospores. However, the more reticulate spore ornamentation, darker spore print, frequently septate pileocystidia and the trichodermal suprapellis clearly set subg. Glutinosae apart from Archaeae. The white spore print mentioned in the original diagnosis of $R$. fattoensis is clearly a mistake that we were able to verify on some of our more recent collections. The most surprising feature for subg. Glutinosae is certainly the septate pileocystidia as this feature is not known from its sister clade (comprised of subgenera Compactae and Archaeae) nor from any other subgenus, apart from subg. Russula.

There is another feature that is very unusual within Russula: the apical swellings of hyphal terminations in the pileipellis. This feature is more or less reminiscent of some species in the crown 
clade, e.g. some members of subsect. Chamaeleontinae (although terminal cells there are more clavate, rather than just having a very restricted inflation near the very apex or near septa). Apical inflations exist to a much lesser degree also in a few species of subg. Archaea, such as in $R$. camarophylla Romagn. (see Buyck et al. 2003). Most recently, Buyck (in Wang et al. 2019b) described $R$. capillaris from Madagascar as a new species in subg. Malodorae (as ' $R$. capillaris sp. ined.' in Buyck et al. 2018). The latter species is strongly reminiscent of subg. Glutinosae as it is not only very similar in the field, but it also possesses similar apical swellings, in this case not only for hyphal terminations in the pileipellis, but also for hymenial gloeocystidia. The morphological similarity is so striking that we (BB) were convinced, when studying it under the microscope, that it would turn out to form a monophyletic group with $R$. glutinosa. Spores, however, are much larger in $R$. capillaris and, again, the pileocystidia are not septate, nor in any of the other species in subg. Malodorae. Therefore, we arrive at a conclusion that the unique combination of unequal lamellae, cream spore print, subreticulate spores, pileipellis hyphae with capitate terminations, and frequently septate pileocystidia distinguishes subg. Glutinosae from all other known subgenera in the genus.

As is often the case for very ancient or isolated lineages, performing nBLAST searches can be quite disorientating considering its fully supported placement that we obtained here in our multigene phylogenetic analysis. Subgenus Glutinosae offers a classic example illustrating that one should not blindly trust BLAST results (see Hofstetter et al 2019), as is most frequently done, to determine the sampling of "closely related" species in phylogenetic approaches. Indeed, the first 100 BLAST hits for nrITS sequences (arranged by max score and excluding environmental sequences) do not list a single species that belongs to either one of the two subgenera that are most closely related to it according to our multilocus analysis: viz. subgenera Compactae and Archaeae. On the contrary, all of the other subgenera show up in the first 100 BLAST results. Since all produced ITS sequences were identical for all American specimens of $R$. glutinosa, as well as for both Chinese specimens of $R$. glutinosoides, there is nothing wrong with the quality of the obtained sequences. Yet, the singularity of the ITS region for species in $R$. subg. Glutinosae probably explains why $R$. glutinosa was never part of any previous phylogenetic study in Russula, notwithstanding that the ITS sequence of $R$. glutinosa was deposited on GenBank more than 15 years ago.

Performing BLAST searches using protein coding genes appears more accurate towards suggesting correct affinities for these species, at least nBLAST of RPB2 sequences listed two members of subg. Archaea as top score results, followed then by species of subgenera Brevipedum, Crassotunicatae and Heterophyllidiae (Cyanoxanthinae in particular). None of the RPB2 BLAST results score higher than $84 \%$ similarity for an acceptable query coverage. BLAST searches using $R P B 1$ sequences are different again with nearly all top scores (similarity $<93 \%$ ) comprising species of subg. Russula. The above illustrates once more the difference between similarity searches and phylogenetic analyses, the latter being here exclusively based on the unambiguously alignable regions of the non-coding genes through manual alignment and exclusion of ambiguous regions, and to strictly coding regions for the protein coding genes through the exclusion of spliceosomal introns.

The fact that BLAST results frequently point toward species of subg. Brevipedum subsect. Pallidosporinae Bon, subg. Crassotunicatae and subg. Heterophyllidiae subsect. Cyanoxanthinae, merits also some attention because all of these groups harbour at least some species with more or less unequal lamellae, with spores that are smaller than in the majority of Russula species, and all these groups include at least some representatives with a glutinous or viscose pileipellis (e.g. several Cyanoxanthinae, $R$. crassotunicata in subg. Crassotunicatae, $R$. fuegiana in subg. Brevipedum).

\section{Acknowledgements}

The first author thanks R.H. Petersen and K. Hughes (Knoxville, Tennessee) for inviting him to the 2004 ATBI in the Smoky Mountains and for producing the ITS sequence for one of the collected specimens; he also thanks the Fatto family for generous hospitality when collecting in 
New Jersey. The Technical Platform for Electron microscopy of the Paris' Museum is thanked for assistance with spore imaging. William Roody is thanked for sharing slides of his collection of $R$. glutinosa. Sequencing of $R$. glutinosa was funded by the national Slovak grant APVV 15-0210. The 2017 joint field trip of BB and XHW in Yunnan was supported by "Investigation of Macrofungi of Maguan County" issued by the Ministry of Ecology and Environment, P.R. China, and the sequencing of $R$. glutinosoides samples was funded by the CAS Key Laboratory for Plant Diversity and Biogeography of East Asia, Kunming Institute of Botany, Chinese Academy of Sciences (project no. LPB201501). Finally, sincere thanks are due to K. Bensch (Mycobank) and Shaun Pennycook (Landcare Research, NZ) for suggesting the nomenclatural corrections of subgeneric taxa in Russula.

\section{References}

Adamčík S, Caboň M, Looney B, Wisitrassameewong K et al. 2019 - The quest for a globally comprehensible Russula language. Fungal Diversity 99: 369-449. https://doi.org/DOI 10.1007/s13225-019-00437-2

Alfaro ME, Zoller S, Lutzoni F. 2003 - Bayes or bootstrap? A simulation study comparing the performance of Bayesian Markov chain Monte Carlo sampling and bootstrapping in assessing phylogenetic confidence. Molecular Biology and Evolution 20(2):255-66

Bazzicalupo AL, Buyck B, Saar I, Vauras J et al. 2017 - Troubles with mycorrhizal mushroom identification where morphological identification lags behind barcode sequence divergence. Taxon 66(4): 791-810.

Buyck B. 1989 - Valeur taxonomique du bleu de crésyl pour le genre Russula. Bulletin trimestriel de la Société mycologique de France 105 :1-6.

Buyck B. 1998 - Une révision critique de la sect. Archaeinae (Russula, Russulales). Belgian Journal of Botany 131 (2): 116-126.

Buyck B. 2004 - Short diagnoses and descriptions of some exotic Russula (Basidiomycotina). Cryptogamie, Mycologie 25(2): 181-182.

Buyck B, Adamčík S. 2013 - Type studies in Russula subsection Lactarioideae from North America and a tentative key to North American species. Cryptogamie, Mycologie 34(3): 259-279

Buyck B, Duhem B, Das K, Jayawardena RS, Niveiro N et al. 2017 - Fungal biodiversity Profiles 21-30. Cryptogamie, Mycologie 38(1): 101-146

Buyck B, Heriveau P, Martin P. 2003 - Quelques récoltes récentes de Russula camarophylla Romagnesi. Bulletin trimestriel de la Société mycologique de France 119: 217-229.

Buyck B, Hofstetter V, Eberhardt U, Verbeken A, Kauff F. 2008 - Walking the thin line between Russula and Lactarius: the dilemma of Russula subsect Ochricompactae. Fungal Diversity 28:15-40

Buyck B, Zoller S, Hofstetter V. 2018 - Walking the thin line.... Ten years later: the dilemma of above- versus below-ground features to support phylogenies in the Russulaceae (Basidiomycota). Fungal Diversity 89(1): 267-292.

Caboň M, Eberhardt U, Looney B, Hampe F et al. 2017 - New insight in Russula subsect. Rubrinae: phylogeny and the quest for synapomorphic characters. Mycological Progress 16:877-892. https://doi.org/10.1007/s11557-017-1322-0

Doyle JJ, Doyle JL. 1987 - A rapid DNA isolation procedure for small quantities of fresh leaf tissue. Phytochemical Bulletin 19:11-15.

Fatto RM. 1999 - Three new species of Russula. Mycotaxon 70: 167-175.

Gardes M, Bruns TD. 1993 - ITS primers with enhanced specificity for basidiomycetes application to the identification of mycorrhizae and rusts. Molecular Ecology 2:113-118. https://doi.org/10.1111/j.1365-294X.1993.tb00005.x 
Heim R. 1938 - Les Lactario-russulés du domaine oriental de Madagascar, essai sur la classification et la phylogénie des Astérosporales. Prodrome à une flore mycologique de Madagascar et dépendances I: 196 pp, 4 pl

Hofstetter V, Buyck B, Eyssartier G, Schnée S, Gindro K. 2019 - The unbearable lightness of sequenced-based identification. Fungal Diversity 96(1): 243-284.

Hongsanan S, Hyde KD, Bahkali AH, Camporesi E et al. 2015 - Fungal Biodiversity Profiles 1120. Cryptogamie, Mycologie 36(3):355-380

Kornerup A, Wanscher JH. 1978 - Methuen handbook of color, $3^{\text {rd }}$ Ed., Eyre Methuen Ltd, UK

Looney BP, Ryberg M, Hampe F, Sánchez-García M, Matheny PB. 2016 - Into and out of the tropics: global diversification patterns in a hyper-diverse clade of ectomycorrhizal fungi. Molecular Ecology 25:630-647.

Matheny PB. 2005 - Improving phylogenetic inference of mushrooms with RPB1 and RPB2 nucleotide sequences (Inocybe; Agaricales). Molecular Phylogenetics and Evolution 35:1-20. doi:10.1016/j.ympev.2004.11.014

Maddison DR, Maddison WP. 2002 - MacClade: analysis of phylogeny and character evolution, version 4.05. Sinauer Associates Inc., Sunderland, Massachusetts, USA

Matsuda Y, Okochi S, Katayama T, Yamada A, Ito S. 2011 - Mycorrhizal fungi associated with Monotropastrum humile (Ericaceae)in central Japan. Mycorrhiza 21(6):569-576.

Miller MA, Pfeiffer W, Schwartz T. 2010 - Creating the CIPRES science gateway for inference of large phylogenetic trees. In Institute of Electrical and Electronics Engineers (Ed.), Proceedings of the gateway computing environments workshop (GCE) (pp. 1-8). New Orleans, LA: IEEE Xplore

Moncalvo JM, Lutzoni FM, Rehner SA, Johnson J, Vilgalys R. 2000 - Phylogenetic relationship of agaric fungi based on nuclear large subunit ribosomal DNA sequences. Systematic Biology 49(2):278-305. https://doi.org/10.1093/sysbio/49.2.278

Morehouse EA, James TY, Ganley ARD, Vilgalys R et al. 2003 - Multilocus sequences typing suggests the chytrid pathogen of amphibians is a recently emerged clone. Molecular Ecology 12:395-403

Ondrušková E, Jánošíková Z, Kádasi-Horáková M, Koltay A et al. 2017 - Distribution and characterization of Dothistroma needle blight pathogens on Pinus mugo in Slovakia. European Journal of Plant Pathology 148(2):283-294. https://link.springer.com/article/10.1007/s10658-016-1088-2

Pastirčáková K, Adamčíková K, Pastirčák M, Zach P et al. 2018 - Two blue-stain fungi colonizing Scots pine (Pinus sylvestris) trees infested by bark beetles in Slovakia, Central Europe. Biologia 73(11):1053-1066. https://link.springer.com/article/10.2478/s11756-018-0114-6

Rehner SA, Buckley E. 2005 - A Beauveria Phylogeny Inferred from Nuclear ITS and EF1- $\alpha$ Sequences: Evidence for Cryptic Diversification and Links to Cordyceps Teleomorphs. Mycologia 97:84-98. http://dx.doi.org/10.3852/mycologia.97.1.84

Stamatakis A. 2008 - A rapid bootstrap algorithm for the RAxML Web servers. Systematic Biology 57(5):758-71. doi: 10.1080/10635150802429642

Stamatakis A. 2014 - RAxML version 8: a tool for phylogenetic analysis and post-analysis of large phylogenies. Bioinformatics 30(9):1312-1313

Wang J, Buyck B, Wang XH, Bau T. 2019a - Visiting Russula (Russulaceae, Russulales) with samples from southwestern China finds one new subsection of Heterophyllidia with two new species. Mycological Progress 18: 771-784.

Wang XH, Das K, Bera I, Chen YH et al. 2019b - Fungal Biodiversity Profiles 81-90. Cryptogamie, Mycologie 40(5): 57-95.

White TJ, Bruns T, Taylor LS. 1990 - Amplification and direct sequencing of fungal ribosomal RNA genes for phylogenetics. In: Innis MA, Gelfand DH, Sninsky JJ, White TJ (eds) PCR protocols: a guide to methods and application. Academic Press, Inc., San Diego, pp 322-315. 